\title{
A ATUAÇÃO DO PSICÓLOGO ESCOLAR: MULTIRREFERENCIALIDADE, IMPLICAÇÃO E ESCUTA CLÍNICA
}

\author{
João Batista Martins
}

\begin{abstract}
RESUMO. Este artigo discute a noção de clínica no contexto da psicologia escolar. Na medida em que nós sugerimos como metodologia de pesquisa e de intervenção para o psicólogo escolar a observação participante, entendemos que tal discussão também se refere a questões epistemológicas - uma vez que a produção de conhecimento se dá na ordem da implicação, pois é construção intersubjetiva. Além disso, considerando a complexidade do cotidiano escolar, apresentamos a abordagem multirreferencial e a escuta clínica como perspectivas para a compreensão dos fenômenos que ali se desenrolam.
\end{abstract}

Palavras-chave: psicologia escolar, multirreferencialidade, escuta clínica.

\section{THE PERFORMANCE OF A SCHOOL PSYCHOLOGIST: MULTI-REFERENTIALITY, IMPLICATIONS AND CLINIC LISTENING}

\begin{abstract}
This article discusses the notion of clinic in the school psychology context. As we suggest the participant observation as research methodology and of intervention for the school psychologist, we understand that such discussion also refers to epistemological questions - once the knowledge production occurs in the order of implication, because it is an intersubjective production. Besides, considering the complexity of the school quotidian, we present the multi-referential approach and clinic listening as perspectives for the understanding of the phenomena that are developed in the school context.

Key words: school psychology, multi-referential approach, clinic listening.
\end{abstract}

Em minha prática docente é comum discutir com meus alunos sobre o campo da Psicologia Escolar, e a pergunta mais freqüente que me é colocada diz respeito à postura e ao papel do psicólogo no contexto escolar. De certa forma, o que os alunos me solicitam expressa a necessidade de estabelecermos uma diferença entre os campos de atuação profissional do psicólogo, quais sejam: psicologia clínica, psicologia organizacional e a psicologia escolar.

Esta discussão é muito antiga no contexto da psicologia. No que diz respeito à identidade do psicólogo escolar, geralmente ela passa pela superação do modelo médico (o que nos remeteria para os fundamentos da psicologia clínica), que estabelece seus parâmetros em torno da dicotomia saúde $\mathrm{x}$ doença, normal x anormal, enfatizando-se o papel de educador que este profissional pode assumir quando atua no contexto da escola.

É esta posição que encontramos num texto de Roger Reger intitulado Psicólogo escolar: educador ou clínico? De acordo com esse autor, à medida que um número maior de psicólogos passou a fazer parte das escolas públicas, questões que dizem respeito ao seu papel tornaram-se importantes, e, segundo ele, determinar qual o papel do psicólogo escolar ajudaria a esclarecer vários problemas que atualmente não podem ser focalizados.

Para Reger, o psicólogo atuaria como clínico no contexto escolar quando baseia sua intervenção num modelo médico. "Seu interesse gira em torno da saúde e da doença mental e do diagnóstico e cura de problemas de comportamento." (Reger, 1989, p. 13). Para ele há um modelo mais apropriado para o profissional que deseja atuar no contexto escolar, qual seja, assumir um papel de educador. Nesse sentido, seu objetivo seria o de "ajudar a aumentar a qualidade e a eficiência do processo educacional através da aplicação dos conhecimentos psicológicos (...) Ele está nas escolas para ajudar a planejar programas educacionais para as crianças" (p.13).

Reger (1989) também afirma que, além de um profissional,

\footnotetext{
* Departamento de Psicologia Social e Institucional - Universidade Estadual de Londrina. Doutor em Educação pela Universidade Federal de São Carlos - UFSCar
} 
(...) o psicólogo escolar é um cientista, um engenheiro educacional ou projetista de planos educacionais que usa das mais modernas metodologias e técnicas. À medida que busca utilizar o sistema educacional tão efetivamente quanto possível para cada criança ou grupos de crianças, tem muito em comum com o administrador educacional e com o professor. Assim como os outros educadores, ele daria mais ênfase ao crescimento e desenvolvimento da criança do que à 'patologia'. Mas diferencia-se do administrador e do professor conforme visa à aplicação mais consistente do método científico na resolução e problemas educacionais e psicológicos. (p. 14)

Ainda segundo o autor, o psicólogo escolar seria um elo entre o mundo acadêmico e o sistema escolar. O psicólogo escolar serve, no modelo clínico, como elo entre várias agências de saúde mental e o sistema escolar. Enquanto agente de ligação entre o mundo acadêmico e o sistema escolar, o psicólogo escolar está interessado em metodologias científicas e resultados de pesquisas, geralmente obtidos no ambiente acadêmico.

Enquanto profissional vinculado ao campo educacional, traduziria estas metodologias e resultados em ação nas escolas. Fazendo isso, poderia atender a dois objetivos: ajudar a superar o descompasso entre educação e aplicação de resultados de pesquisa e encorajar atividades de pesquisa nas escolas, servindo como elemento de ligação para os acadêmicos que queiram fazer contato com indivíduos que falem a sua linguagem nas escolas. Como educador comprometido com a identidade acadêmica, pode também tentar ensinar a outros profissionais no sistema escolar, fornecendo condições de aprendizagem para os que podem tomar as melhores decisões referentes a programas educacionais. "O psicólogo escolar experiente poderia exercer com facilidade os papéis de consultor, orientador, professor e pesquisador." (Reger, 1989, p.15)

Uma outra caracterização do trabalho do psicólogo escolar é proposta por Carmem S. de A. Andaló, que, em 1984, publicou um texto intitulado $O$ papel do psicólogo escolar, onde discute a inserção desse profissional no âmbito da escola. Para ela, a psicologia escolar é considerada uma área secundária da psicologia, que não requer muito preparo nem experiência profissional. Dentro da escola, o psicólogo é pouco valorizado ou mesmo considerado dispensável, pois inexistem serviços dessa natureza. Tal perspectiva talvez seja proveniente do fato de que a área escolar foi caracterizada historicamente como um desmembramento da área clínica, gerando uma visão de psicologia escolar clínica.

Segundo a autora, os psicólogos escolares têm feito um trabalho clínico dentro da escola, usando testes variados, como de QI, de personalidade, e elaborando diagnósticos e orientações detalhadas, ou então, oferecendo psicoterapia para os alunos considerados como portadores de distúrbios emocionais, de conduta, e até mesmo de psicomotricidade. Tal atitude pode acarretar em uma série de problemas, como o risco de discriminar e estigmatizar os alunos que se beneficiam desta forma de serviço. O sigilo pode não ser mantido pelos próprios alunos, uma vez que a escola é uma organização onde a privacidade é restrita etc.

Sob a perspectiva da "psicologia escolar clínica", o trabalho do psicólogo tem como papel evitar desajustes ou desadaptações do aluno. Estes, por sua vez, são equacionados em termos de saúde $\mathrm{x}$ doença, $\mathrm{o}$ que, na escola, é retraduzido como problemas de ajustamento e adaptação. A escola, como instituição, é tomada como adequada, cumpridora dos objetivos ideais que foram propostos.

De certa forma, sob a perspectiva acima, os problemas que surgem no contexto escolar são centrados nos alunos, e investe-se o psicólogo de um caráter de onipotência, e seu papel acaba sendo tratar estes 'alunos-problema', devolvendo-os à sala de aula 'bem-adaptados'. Isso leva, freqüentemente, a uma atitude de ambivalência e resistência por parte da instituição escolar, que muitas vezes dificulta ou até mesmo impede a continuidade dos serviços de psicologia.

A alternativa mais adequada para a intervenção do psicólogo no contexto escolar sugerida por Andaló (1984) é aquela em que, sem excluir as contribuições da psicologia clínica e acadêmica, o profissional assuma o papel de agente de mudanças dentro da instituição escolar. Ele atuaria como um elemento centralizador de reflexões e conscientizador dos papéis representados pelos vários grupos que compõem tal instituição. Ou seja, em vez de abordar os problemas escolares centrando seu olhar sobre os alunos, o psicólogo atuaria sobre as relações que se estabelecem neste contexto, levando em consideração o meio social em que estas relações estão inseridas e o tipo de clientela que atende, assim como os grupos que a compõem. Ele atuaria, portanto, sobre a instituição escolar ${ }^{1}$.

Nossa experiência no atendimento às demandas das escolas no contexto da cidade de Londrina, no

Mais detalhes sobre essa perspectiva, ver Andaló, 1993. 
entanto, tem demonstrado que as coisas não são tão claras assim. Apesar das mudanças ocorridas no contexto das teorias psicológicas e educacionais, as expectativas sociais acerca do trabalho do psicólogo na escola ainda esbarram no modelo médico. Uma pesquisa realizada em 1994, junto às escolas que recebem atendimento da Área de Psicologia Escolar do Departamento de Psicologia Social e Institucional/UEL, revelou que as solicitações de trabalho feitas por estas instituições estavam diretamente relacionadas ao "modelo médico" referido anteriormente - esperava-se que as crianças com dificuldades fossem tratadas fora do contexto escolar e, após "a cura", fossem novamente inseridas nas salas de aula (Costa, Kumata \& Siqueira, 1994).

Machado e cols. (1993), numa investigação sobre a relação do psicólogo escolar com outros profissionais em escolas (públicas e particulares) da cidade de Ribeirão Preto, nos mostram que a função mais exercida por estes profissionais no contexto escolar é a de mantenedor da disciplina escolar entendida como uma "ação de suspensão de alunos quando necessário, conversa com pais tendo em vista a adaptação escolar dos alunos às normas da instituição." (p. 51).

Tais fatos revelam a dificuldade da inserção do psicólogo no contexto escolar sob novas perspectivas perspectivas que superem o modelo médico. No entanto, entendemos que a tentativa de Reger (1989) em atribuir a priori uma série de papéis ao psicólogo escolar não avança na superação destas dificuldades, uma vez que o lugar ocupado por esse profissional na instituição escolar se estrutura em função do contexto e do cotidiano institucional.

Já a perspectiva desenhada por Andaló (1984, 1993) - uma inserção profissional que tenha como perspectiva a instituição - se revela mais promissora. Em que pese às expectativas sociais atribuídas ao psicólogo escolar, este deve compreender os fatores sociais e institucionais que possibilitaram a emergência das representações a respeito de seu trabalho - seja no contexto escolar, seja no contexto social em que está inserido - pois será no âmbito das relações que estabelece no interior da instituição escolar que terá condições de proporcionar novas alternativas para seu trabalho.

É no âmbito desta perspectiva - a institucional que apresentamos a abordagem multirreferencial como uma possibilidade analítica e de intervenção para este profissional, uma vez que ela assegura a complexidade do contexto escolar. Além disso, tal abordagem coloca questões epistemológicas e metodológicas, uma vez que psicólogo escolar se vê às voltas com vínculos de diversas ordens (conscientes e/ou inconscientes), que o implicam,o capturam e estão presentes em seu campo de trabalho, vínculos estes que devem ser reconhecidos. Nesse sentido, o trabalho do psicólogo se inscreve na ordem da intersubjetividade, do vivido, da experiência, o que nos leva a reconsiderar a questão da clínica no âmbito da psicologia escolar enquanto uma escuta clínica, caracterizando o trabalho do psicólogo como uma espécie de acompanhamento dos fenômenos que emergem no cotidiano escolar. Tais dimensões serão ampliadas e discutidas nas sessões que se seguem.

\section{MULTIRREFERENCIALIDADE E IMPLICAÇÃO}

Em 1996 (Martins, 1996) indicava que o psicólogo, ao tomar o cotidiano escolar como o espaço para sua intervenção, utilizando-se da metodologia da observação participante, teria acesso às várias dimensões da instituição - a sua história documentada e a sua história não-documentada, conforme nos diz Ezpeleta e Rockwell (1986) - o dito e o não-dito na perspectiva da análise institucional (Lourau, 1995. Martins, 2000).

O mesmo autor apontava ainda que, ao intervir no cotidiano, o psicólogo propiciaria situações onde as práticas sociais teriam condições de ser ressignificadas, assim como a percepção acerca da sua atuação. A estruturação do trabalho deveria, portanto, envolver o coletivo escolar, assegurando e proporcionando a participação democrática de todos os segmentos que vivenciam a escola.

Tal fato, por sua vez, nos leva a compreender a escola como um campo propício para a emergência das contradições socioculturais e econômicas que marcam nossa sociedade, e nossa intervenção pode propiciar a expressão destas contradições através da organização dos diversos segmentos (estudantes, pais, professores, etc.) que participam de seu cotidiano. Tal possibilidade de trabalho permite uma reflexão acerca dos objetivos da escola, seus procedimentos, seus métodos de avaliação, e um redirecionamento de suas práticas - assegurando-se assim o processo de democratização da escola.

Como podemos observar, ao considerar estas dimensões acerca da instituição escolar, o "olhar" do psicólogo se amplia: multirreferencializa-se e se complexifica ${ }^{2}$. Isto significa, por sua vez, reconhecer que o fenômeno educativo e seus desdobramentos

\footnotetext{
2 A idéia de complexidade aqui referida está vinculada à obra de Edgard Morin. Mais detalhes ver Morin, 1996a e 1996b.
} 
psicológicos se dão em várias dimensões - a dos sujeitos, a dos grupos, a da organização, a da instituição e a da sociedade - e que a psicologia exclusivamente - não dá conta de explicitar todas as suas nuanças.

Destarte, para compreendermos um pouco melhor os fenômenos que se apresentam no contexto escolar, temos que lançar mão de outras disciplinas sociologia, antropologia, psicanálise, economia, psicologia social, psicossociologia, etc. A complexidade destes fenômenos nos incita a abordálos multirreferencialmente - a partir de várias referências teóricas ${ }^{3}$.

Cabe ressaltar que a análise multirreferencial aqui proposta não tem como pretensão "esgotar" seu objeto de estudo. Analisar, neste contexto, não se define mais através da nossa capacidade de recortar, de decompor, de dividir, reduzir a elementos mais simples, mas através de nossas possibilidades de "compreensão", de "acompanhamento" dos fenômenos vivos e dinâmicos (Ardoino, 1995, p. 9).

Tal postura nos aproxima de um tipo específico de metodologia de trabalho que tem como pressuposto o reconhecimento do caráter implicacional da atividade de pesquisa ou de intervenção.

Ao indicar a observação participante como uma metodologia de trabalho para o psicólogo escolar, Martins (1996) quis enfatizar que esse profissional ao se inserir no contexto escolars se confronta com uma certa tensão. De um lado, ele deve estabelecer um certo distanciamento do seu objeto de estudo e de intervenção, de tal modo que possa conhecer seus interstícios; por outro lado, deve buscar estabelecer uma relação de implicação junto aos agentes envolvidos no processo, sem a qual seria impossível desenvolver sua atividade.

Tal fato, por sua vez, traz em si mesmo um problema epistemológico, que diz respeito, fundamentalmente, à questão da relação entre sujeito e objeto. Como assinala Bohoslavsky (1976):

El psicólogo tiene en su cuenta ... que su rol
de observador modifica, aun por su sola
presencia, el campo de observación; es, por
lo tanto, un observador participante y
consciente de esa participación en el
fenómeno que está bajo su mirada. Al
observar una situación, está por consiguiente
observándose a sí mesmo y al vínculo que ha

3 O conhecimento produzido sob esta perspectiva aproximarse-ia da atividade da bricolagem, pois tais disciplinas seriam operacionalizadas de tal forma que elas não se reduzissem umas às outras, conforme nos indica Ardoino, 1998 e Lapassade, 1998. Ver também, Martins, 2000. estabelecido con ella. Es dicer, conforma un nuevo campo del qual, a la vez que forma parte, se distancia, efectuando lo que se ha lhamado una "disociación instrumental": es objeto que participa de la situación y por ende la condiciona $\mathrm{y}$, al mismo tiempo, sujeto que se auto-observa a fin de discriminar cómo y quánto condiciona su presencia la situación que estudia. (p. 20-1)

Isto significa dizer que a possibilidade de pesquisa/intervenção será circunscrita na/pela interatividade: o conhecimento e a prática profissional se realizam na/pela relação mesma entre sujeito e objeto - na relação intersubjetiva.

Nesse sentido, o trabalho do psicólogo escolar não é neutro e nem objetivo, pois além de ele não dominar (no sentido de controle) seu objeto - a dinâmica da escola - ele está implicado com (n)ele. ${ }^{4}$

Queremos dizer com isso que esta relação psicólogo x "escola" - entendida como um encontro intersubjetivo, requer o reconhecimento de dimensões que não estão relacionadas nem com os aspectos teóricos nem com os aspectos metodológicos que ele pode utilizar quando da realização de seu trabalho. Tais dimensões estão circunscritas pela ordem do psíquico, do desejo, da vontade, que implicam afetos nem sempre "dizíveis" no cotidiano acadêmico, mas que emergem durante a inserção profissional. ${ }^{5}$

\section{A ESCUTA CLÍNICA}

É no contexto das considerações anteriores que vislumbramos a "escuta clínica" como uma forma de abordar os fenômenos que se desenrolam no cotidiano escolar.

Tradicionalmente o termo clínico, seja ele empregado como substantivo, seja como adjetivo, indica ou um tipo de prática, de experiência, de formação, ou um estabelecimento onde as pessoas

4 Entendemos implicação como o “... engajamento pessoal e coletivo do pesquisador em e por sua práxis científica, em função de sua história familiar e libidinal, de suas posições passadas e atual nas relações de produção e de classe, e de seu projeto sócio-político em ato, de tal modo que o investimento que resulte inevitavelmente de tudo isso seja parte integrante e dinâmica de toda atividade de conhecimento." (Barbier, 1985, p. 120)

5 Muitas vezes as informações provenientes deste tipo de experiência são registradas em nossas anotações, em nossos cadernos de campo, e "lapidados" e "re-elaborados" sob o prisma da razão. Sobre esta questão ver Borba, 1997, especialmente o capítulo intitulado "Jornal de Pesquisa". 
procuram um tratamento para suas doenças: clínica psicológica, clínica médica etc.

No âmbito da medicina, este termo nos remete para o trabalho do médico junto a seu paciente, o que traz implícita a idéia de uma certa evolução favorável da doença que o paciente apresenta, em função da atenção que ele recebe ${ }^{6}$. Nesse sentido, entende-se que há uma certa relação entre o conceito de clínico e a noção de mudança - o que implica uma dimensão histórica. No entanto, Ardoino (1990) nos alerta que as expectativas implícitas nestas mudanças estão relacionadas com um retorno a uma norma, a uma situação anterior e a ação do médico será reparatória, pressupondo-se o restabelecimento de um estado considerado anteriormente como "normal".

No âmbito das Ciências do Homem e da Sociedade, o sentido original do termo clínico, encontra-se consideravelmente modificado ${ }^{7}$. A questão não está mais colocada sobre uma qualidade ou estado de um paciente, o que demandaria um certo tipo de trabalho e, por conseqüência, uma determinada prática e/ou metodologia de intervenção, mas "[O] projeto do clínico está-se tornando fundamental para a inteligibilidade de sua prática. Ao questionamento metodológico se superpõe... uma interrogação epistemológica." (Ardoino, 1990, p. 37).

De uma certa maneira, as considerações tradicionais sobre o clinicar nos remete para um tipo de familiaridade (com o "doente"), para o conhecimento pela experiência. Mas, à essas idéias, acrescenta-se, atualmente, a idéia de intervenção do prático e o postulado de uma capacidade de evolução, de aquisições, que se dão pela integração e pelo jogo de alterações ${ }^{8}$. Nesse sentido Ardoino afirma: "É justamente essa hipótese de transformações possíveis, (...), que se torna essencial quando se trata de práticas sociais definidas como clínicas." (1990, p. 37).

Apesar de ainda encontrarmos o emprego do termo "clínico" em sua acepção original, vinculando-o

6 Etimológicamente "clínica" deriva de "cama". Utilizado para caracterizar la labor de los médicos, este término señala el trabajo concreto sobre un paciente específico. Luego se extiende hasta abarcar un ámbito geográfico: el hospital, o una rama de las enseñanzas médicas. (Bohoslavsky, 1976, p. 23, n. 3)

7 Ver Lévy (2001) e Araújo e Carreteiro (2001).

8 A alteração é entendida aqui como uma dinâmica onde se reconhece que numa relação entre pessoas, elas se influenciarão entre si, modificando-se. Neste processo estão implícitos não apenas os aspectos conscientes de cada um, mas também esse processo é marcado por desejos, vontades etc. traços muito mais relacionados com o inconsciente. à ação do médico sobre o doente; as práticas sociais que implicam alterações, como é o caso tanto das psicoterapias e socioterapias, como em certos aspectos da educação, da formação etc., trazem novos sentidos para o termo. Estes últimos, por sua vez, incorporamse ao sentido original, ampliando-o, suportando algumas contradições, o que o localiza no âmbito de uma certa polissemia.

A noção de clínico, portanto, se inscreve na ordem da praxiologia, enquanto ação-reflexão, seja no âmbito da escola, seja no âmbito do hospital... Assim, "clínico" passa a ser um "conceito chave, na confluência da ciência fundamental com a ciência aplicada no que se refere ao homem." (Barbier, 1985, p. 46).

\section{Para Ardoino:}

(...) o procedimento clínico e sua teorização devem conquistar o lugar que lhes foi até agora recusado (...) o que é fundamental ao procedimento clínico é o respeito, ou melhor, a sensibilidade ao que é ambíguo, ao duplo sentido e à hipercomplexidade. (Ardoino citado por Barbier, 1985, p. 46)

Podemos caracterizar o olhar clínico como aquele que toma em consideração um campo - de pesquisa ou de intervenção - estruturado por um jogo de relações e de interações dinâmicas e complexas. No entanto, ele também supõe que o prático e o pesquisador estejam convenientemente deslocados na relação, isto é, que eles assumam uma postura de implicação-distanciamento. Tal postura, por sua vez, possibilitar-lhes-á estar efetivamente co-presentes na situação que eles analisam, sem perder, para tanto, suas especificidades e suas competências.

Da Matta (1987) aproxima-se bastante desta perspectiva ao analisar possibilidades do trabalho antropológico no âmbito das sociedades em que o antropólogo está inserido. Ele nos aponta que a tarefa do antropólogo nessa situação será transformar o que lhe é "familiar" em "exótico". Isto requer, o que podemos denominar de uma atitude de "estranhamento" para o que é vivenciado como rotineiro, comum, próximo, conhecido etc., o que significa, concomitantemente, um "estranhamento de si mesmo", um "auto-estranhamento". Tal atitude, portanto, implica a busca de novos sentidos para a relação que o antropólogo estabelece com seu objeto, reconhecendo nela - na relação - a possibilidade de dar novos sentidos para as suas próprias representações.

Ardoino, por sua vez, nos lembra, nesse caso 
(...) o tipo de análise em questão não tem mais grande relação com a análise entendida etimologicamente (decomposição, redução do complicado em elementos mais simples) É mais uma sagacidade (perspicácia), vinculada a um processo de acompanhamento numa duração, a intimidade partilhada, donde (...) os exemplos: psicanalítico, socioanalítico, etnológico, etnográfico, e até etnometodológico, podem nos dar alguma idéia. (Ardoino, 1990, p. 38)

Cabe salientar que a clínica se apóia fundamentalmente na observação - no olhar mais ou menos caracterizado por uma ambição de controle, como o que caracteriza a postura médica tradicional. No entanto, quando à ela (à observação) aproximamos a importância da escuta, mais temporal, aquela do não-dito. "O ouvido aí se encontra assim conjugado com o visto." (Ardoino, 1990, p. 39).

Isto significa que as funções do "olhar" e da "escuta", que se apóiam sobre visões de mundo diferentes - ou seja, implicam paradigmas diferentes (os primeiros mais voltados para dimensões espaciais enquanto que os relativos ao segundo mais voltados para as dimensões temporais) e consequientemente em metodologias específicas - devem ser articuladas convenientemente a fim de estabelecer pontos de referência no tempo e no espaço, concomitantemente.

Para Ardoino há nessa escuta, como na interpretação que a acompanha, uma primeira forma de multirreferencialidade

(...) é a língua do outro, sua indexicabilidade que é necessário apreender e falar, para encontrar os fios de sua pré-história e os avatares de seu desejo. [Na relação clínica] o discurso não tem necessidade de ser explícito pois ela joga essencialmente ao nível do subentendido. (Ardoino, 1990, p. 40)

Em vista do reconhecimento da heterogeneidade que a abordagem clínica pressupõe em si mesma, ela é notadamente multirreferencial quando se trata de sujeitos coletivos. Nesse caso, para compreendê-los, é necessário recorrer a “(...)óticas de leitura e de linguagem diferentes (psicológica, psicossociológica, sociológica, econômica etc.), heterogêneas, que é necessário saber combinar e articular." (Ardoino, 1990, p. 40).

Tal perspectiva, no plano das práticas do psicólogo escolar, permite o reconhecimento de elementos até então desconsiderados na abordagem dos processos educativos, possibilitando uma reapropriação da experiência e dos sentidos, a eles atribuídos, pela abertura ao desconhecido, pela disponibilidade para a alteração (e por consequiência da heterogeneidade), para a escuta do inefável.

\section{CONSIDERAÇÕES FINAIS}

Abordar a escola multirreferencialmente, o que isso significa para o psicólogo escolar? Tal questão nos remete para várias dimensões da atuação do psicólogo no contexto da escola. Inicialmente cabe registrar que a abordagem multirreferencial possibilita ao profissional compreender a instituição em sua complexidade, abordando os fenômenos que ali se desenvolvem sob várias óticas disciplinares: sociologia, psicologia, antropologia, etc... de tal forma que elas não se reduzam umas as outras. $O$ conhecimento produzido acerca desta realidade é um conhecimento conjugado, tecido, localizado, historicizado; conhecimento que, em princípio, deve ser construído coletivamente.

Cabe registrar que a complexidade não é intrínseca aos fenômenos, mas ela se constrói a partir dos olhares que são colocados sobre ele. Isto significa que a atuação do psicólogo - enquanto pesquisador/interventor no contexto escolar - é marcada pela sua implicação, ou seja, o conhecimento produzido e/ou a intervenção efetivada se circunscrevem a partir relações intersubjetivas que são estabelecidas no cotidiano escolar, o que significa reconhecer a influência do desejo, da vontade, dos afetos etc... que emergem durante sua inserção profissional e que estão presentes (mas muitas vezes negados) nos encontros entabulados na escola.

Abordar multirreferencialmente a instituição escolar significa também assumir uma outra postura em seu cotidiano, uma postura que não se inspire nos modelos positivistas nem cartesianos - cujo objetivo é simplificar a realidade para melhor controlá-la. Uma postura que se estruture numa escuta, numa escuta clínica, que aqui deve ser entendida como uma forma de acompanhamento, um acompanhar da realidade escolar em sua historicidade, resgatando-se o vivido, o experienciado. Não se trata de trabalhar no eixo doença x saúde, como pressupõe Andaló em sua crítica ao modelo médico, mas criar espaços onde as vivências escolares possam ser ditas e escutadas - seja sob na perspectiva da sociedade, seja na perspectiva da instituição, seja na perspectiva dos indivíduos ou grupos, etc...

Tal lugar - o da escuta - possibilita ao psicólogo criar situações coletivas, espaços de construção de conhecimentos sobre si mesmo - sobre a escola, sobre as experiências dos envolvidos no processo 
educacional, etc. - de tal forma que os problemas vividos sejam amplamente discutidos e a busca de soluções para os mesmos, compartilhada. O exercício da escuta clínica, por suas vez, tem como perspectiva desvelar dimensões do cotidiano escolar e das relações que $o$ estruturam até então impensadas, desconhecidas, mas que tangenciam as práticas que aí se estabelecem.

O psicólogo, nesse lugar, tem a condição de sair da desconfortável situação de bombeiro - onde sua ação se restringe a "apagar incêndios" - e contribuir para com a organização dos envolvidos com a escola, criar no coletivo novas pautas de compreensão da realidade vivida, sugerir novas formas de avaliação dos processos que se desdobram no contexto escolar (de aprendizagem, de avaliação, referentes a organização, a instituição, etc...).

Cabe registrar, no entanto, que este lugar que "desenhamos" para o psicólogo não existe, ainda não se consolidou, pois as expectativas depositadas sobre sua atuação ainda se estruturam no eixo doença $x$ saúde.

A mudança, por sua vez, pode ser vislumbrada, desde que seja promovida no contexto das relações sociais que se estabelecem tanto no contexto escolar como na sociedade mais ampla. É no âmbito dessas relações que vislumbramos as possibilidades de mudança, pois é aí que o profissional terá a oportunidade de negociar sentidos, ampliar o significado de sua prática, apresentar novas perspectivas de intervenção e de compreensão da realidade.

\section{REFERÊNCIAS}

Andaló, C. S. A. (1984). O papel do psicólogo escolar. Psicologia, ciência e profissão. 1, 43-47.

Andaló, C. S. A. (1993) O psicólogo escolar na busca de uma identidade. Jornal do Conselho Federal de Psicologia. Ano VIII (34), 5.

Araújo, J. N. G. \& Carreteiro, T. C. (Orgs.) (2001). Cenários sociais e abordagem clínica. São Paulo/Belo Horizonte: Escuta/FUMEC.

Ardoino, J. (1990). L'analyse multiréférentielle des situations sociales. Psychologie Clinique. 3, 33-49.

Ardoino, J. (1995). Multiréferentielle (analyse). En J. Ardoino. Le directeur et l'intelligence de l'organization: Repéres et notes de lecture (pp. 7-9). Ivry: ANDESI.

Ardoino, J. (1998). Abordagem multirreferencial (plural) das situações educativas e formativas. Em J. G. Barbosa
(Coord.). Multirreferencialidade nas ciências e na educação (pp. 24-41). São Carlos: Editora da UFSCar.

Barbier, R. (1985). A pesquisa-ação na instituição educativa. Rio de Janeiro: Jorge Zahar.

Bohoslavsky, R. (1976). Orientación vocacional: la estrategia clínica (3ed.). Buenos Aires: Nueva Visión.

Borba, S. C. (1997). Multirreferencialidade na formação do "professor-pesquisador": da conformidade à complexidade. Maceió: Do Autor.

Costa, A. C.; Kumata, L. Y. \& Siqueira, S. L. (1994). Esclarecimento do papel do psicólogo em instituição escolar e levantamento nas escolas das facilidades/dificuldades encontradas pelos estagiários (mimeo). Relatório de Pesquisa. Londrina: Dep. Psicologia Social e Institucional/UEL.

Da Matta, R. (1987). Relativizando: uma introdução à antropologia social. Rio de Janeiro: Rocco.

Ezpeleta, J. \& Rockwell, E. (1986). Pesquisa participante. São Paulo: Cortez/Autores Associados.

Lapassade, G. (1998). Da multirreferencialidade como "bricolagem". Em: J. G. Barbosa (Coord.). Multirreferencialidade nas ciências e na educação (pp.5165). São Carlos: Editora da UFSCar.

Lévy, A. (2001). Ciências clínicas e organizações sociais. Belo Horizonte: Autêntica/FUMEC.

Lourau, R. (1995). A análise institucional. Petrópolis: Vozes.

Machado, V. L. S., Xavier, A. P. M, Papa, G. R., Wierman, M. L., Castaldelli, V., Domínguez, V. (1993). Psicólogo escolar, orientador pedagógico e assistente pedagógico na escola: um trabalho em cooperação? Paidéia. 4,45-63.

Martins, J. B. (1996). Observação participante: uma abordagem metodológica para a psicologia escolar. Semina: Ciências Sociais/Humanas. 17 (3), 266-273.

Martins, J. B. (2000) Abordagem multirreferencial: contribuições epistemológicas e metodológicas para o estudo dos fenômenos educativos. Tese de Doutorado, Universidade Federal de São Carlos, São Carlos.

Morin, E. (1996a). Epistemologia da complexidade. Em D. F. Schnitman (Org.). Novos paradigmas, cultura $e$ subjetividade (pp. 274-289). Porto Alegre: Artes Médicas.

Morin, E. (1996b). Introducción al pensamiento complejo. Barcelona: Gedisa.

Reger, R. (1989). Psicólogo escolar: educador ou clínico? Em: M. H. Souza Patto (Org.). Introdução à Psicologia Escolar (pp. 9-16). São Paulo: T. A. Queiroz.

Recebido em 11/07/2003 Aceito em 24/09/2003

Endereço para correspondência: João Batista Martins, Rua Anísio Figueiredo, 476 - Londrina - PR. CEP 86065-800. Email: jbmartin@sercomtel.com.br. 